\title{
The skin as a window on internal disorders: Two cases of internal malignancy and hypervitaminosis B12
}

\section{Seetharampura Ramamurthy Radhika ${ }^{1}$, Albur Shankaraiah Nandini², Boothankad Chandregowda Sharath Kumar²}

${ }^{1}$ Department of Dermatology, Venereology and Leprosy Bangalore Medical College and Research Institute, Bengaluru, India, ${ }^{2}$ Department of Dermatology, Venereology and Leprosy Kempegowda Institute of Medical Sciences Hospital and Research Centre, Bengaluru, India

Corresponding author: Dr. Seetharampura Ramamurthy Radhika, E-mail: radhikaramamurthy24@gmail.com

\begin{abstract}
Paraneoplasias are frequently the first sign of an underlying malignant tumor. Although relatively rare, they need to be recognized by dermatologists to make an early diagnosis and improve the neoplastic prognosis. We report two cases of internal malignancy: small cell carcinoma of the lung and cervical carcinoma in stage IIB, detected through paraneoplastic cutaneous manifestations. Raised vitamin B12 levels along with high levels of cobalamin—reported in patients with different types of cancer-were also described in the second case report.
\end{abstract}

Key words: Paraneoplastic cutaneous manifestations; Exfoliative dermatitis; Telogen effluvium,

Hypervitaminosis B12; Tripe palms

\section{INTRODUCTION}

The skin often acts as a mirror of changes internal to the body. Neoplastic diseases affecting the internal organs can lead to different kinds of cutaneous manifestations, thus known as paraneoplastic manifestations [1]. These include exfoliative dermatosis, which may be caused by various drugs, underlying cutaneous disorders—-such as psoriasis, atopic dermatitis, exposure dermatitiscutaneous malignancies such as Sézary syndrome, and solid organ tumors. Determining the cause of erythroderma is essential, but is also quite challenging for the dermatologist [2]. Telogen effluvium (TE) can be due to several conditions, but a sudden onset of TE as the only presentation of complaint in a patient with undetected internal malignancy is notably rare. Pathophysiologically, tumor-related hypervitaminosis B12 is mainly linked to excessive synthesis of transcobalamin by the tumor or high haptocorrin levels due to a leukemoid reaction $[3,4]$. Thus, great suspicion should be exercised upon the diagnosis of hypervitaminosis B12.

\section{CASE REPORTS}

\section{Case 1}

A 70-year-old male presented with 4 weeks of generalized peeling of the skin, accompanied occasionally by mild itching. Upon examination, he was cachectic and had pallor, clubbing, and cervical lymphadenopathy and generalized exfoliation of the skin. The palms and soles showed a thickening velvety appearance, suggesting tripe palms (Fig. 1). A cutaneous and systemic examination was normal except for crepitations present on the right side of the chest. Thus, the patient was diagnosed with internal malignancy, keeping in mind the generalized exfoliative dermatitis and tripe palms as a paraneoplastic condition.

Upon further inquiry, the patient admitted to a history of appetite loss and a weight loss of $5-6 \mathrm{~kg}$ in 1 month. The patient denied fever, cough, chest pain, and dyspnea on exertion. Blood and urine reports were normal except for hemoglobin (9.9) and neutrophilia. A chest X-ray and CECT of the thorax showed a necrotic mass in the

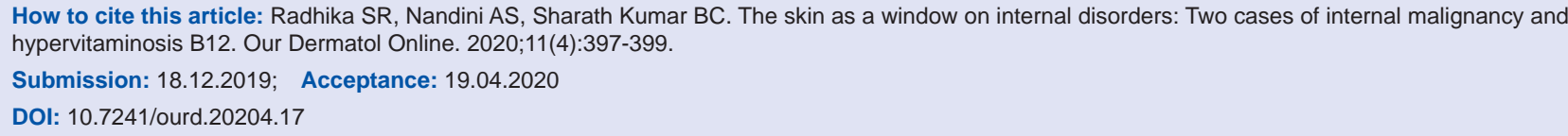


upper right lung lobe with cavitation and mediastinal lymphadenopathy (Fig. 2). A skin biopsy was taken from the palm, showing features of tripe palms. FNAC (Fig. 3a) and a transcutaneous CT-guided lung biopsy were done and revealed small cell carcinoma of the lung (Fig. 3b). An upper GI endoscopy was also done to rule out GI malignancies, showing grade B esophagitis. Thus, the patient was referred to a medical oncologist for further management. The patient died within a few days of referral to a higher center.

\section{Case 2}

Upon further evaluation, the patient gave a history of itching over the vulval area for the past few months. Upon local genital examination, an irregular firm-tohard mass was present in the anterior lip of the cervix, which bled on touch (Fig. 4). A horizontal group of superficial inguinal lymphadenopathy was also present. A cutaneous and systemic examination was normal. A biopsy of the mass was done, showing a carcinoma of the cervix (Fig. 5). Abdominal and pelvic USG showed mild and diffuse thickening of the urinary bladder wall and hydrometra secondary to the obstruction from

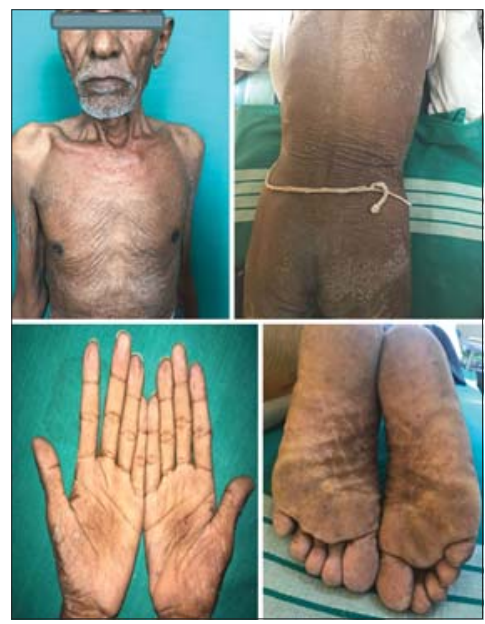

Figure 1: Generalized exfoliation of the skin with tripe palms and soles.

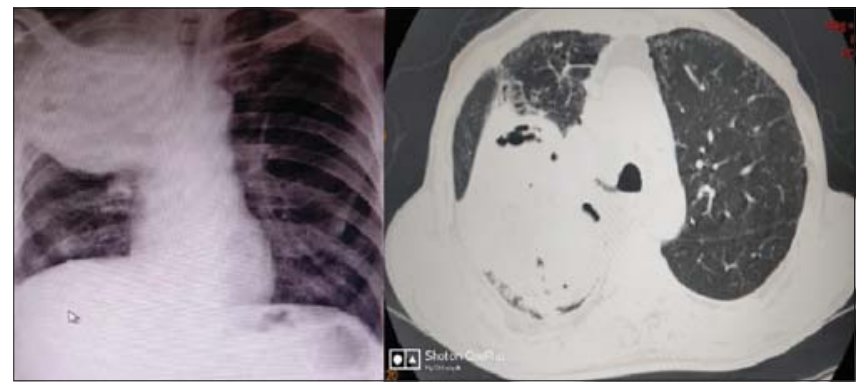

Figure 2: A chest X-ray with an opacity in the upper right and middle zone with air-fluid levels. CECT of the thorax showing a necrotic mass in the upper right lung lobe with cavitation and mediastinal lymphadenopathy. the bulky cervix (enlarged and irregular). A chest X-ray was normal. CT of the pelvis showed a mass in the cervix causing upstream hydrometra, thickening of the entire length of the vagina, and infiltration. After the clinical examination and investigation, the patient was diagnosed with a carcinoma of the cervix in stage IIB. The patient underwent 5 weekly cycles of cisplatin (CT) with concurrent EBRT at a dose of 45 Gy in 25 fractions to the pelvis with a $15 \mathrm{MV}$ beam for 5 weeks. The patient tolerated the treatment well.

\section{DISCUSSION}

A study done on 139 malignant patients demonstrated the association between hypervitaminosis $\mathrm{B} 12$ and solid neoplasms [13]. Hepatocellular carcinoma (HCC), secondary liver tumor, breast cancer, colon cancer, stomach cancer, and pancreatic tumor were some of the relevant carcinomas associated $[14,15]$. The exact pathophysiology of underlying cancer causing high plasma B12 levels has not been well understood. B12 circulates by binding to either haptocorrin or transcobalamin. Cancer may, thus, affect the metabolism of vitamin B12

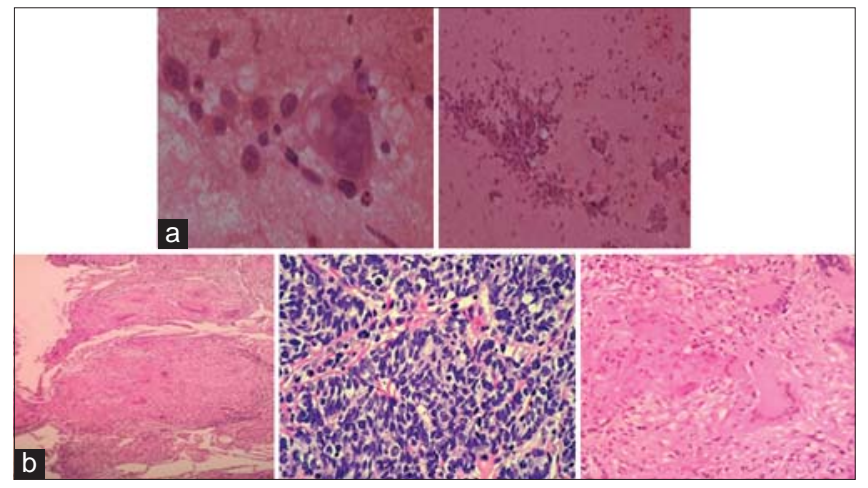

Figure 3: (a) FNAC of the lung showing atypical cells in clusters, individual cells with a high NC ratio, and multinucleated giant cells. (b) A lung biopsy showing nests of tumor cells around a blood vessel, individual cells with minimal cytoplasm, hyperchromatic nuclei, atypical cells arranged in clusters with a high nucleus-cytoplasmic ratio, a moderate amount of cytoplasm, a vesicular nucleus, and prominent nucleoli.

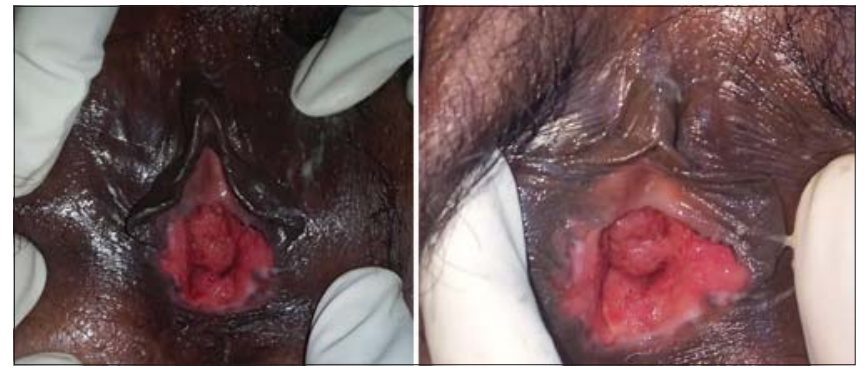

Figure 4: An irregular firm-to-hard $2 \times 3 \mathrm{~cm}$ mass present over the anterior lip of the cervix. 


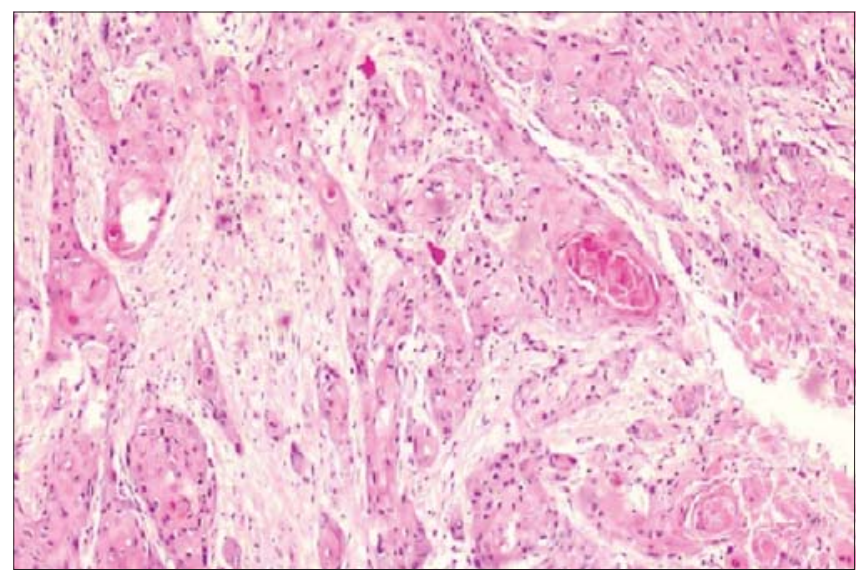

Figure 5: H\&E stain showing malignant squamous cells that form irregular nests invading the stroma, laminated keratin pearls in the center of the nest, and individual cells with abundant eosinophilic keratinized cytoplasm.

by affecting the levels of these binding proteins, in turn leading to hypervitaminosis B12. These protein alterations may involve inflammation cells that can produce either haptocorrin or transcobalamin. This potential underlying inflammation could explain the association between high plasma B12 levels and the higher mortality risk, and also the risk of venous thromboembolism in carcinoma patients [16]. J.F.H. Arendt et al. [4] conducted a population-based cohort study using data from Danish medical registries, including 25,017 patients with cancer and varied cobalamin levels, and a comparison cohort of 61,988 cancer patients without a plasma cobalamin measurement. The conclusion was that cancer patients with elevated cobalamin levels had higher mortality rates than patients without elevated cobalamin levels. According to another study, which was conducted in UK primary care, concluded that elevated plasma B12 levels were associated with higher yearly cancer risk than normal B12 levels, also suggesting that some cancers may affect B12 metabolism [16].

\section{CONCLUSION}

This paper highlights the importance of generalized exfoliation, tripe palms, sudden-onset hair loss, and high levels of vitamin B12 as paraneoplastic conditions. The importance of a detailed medical history, general physical examination, and evaluation with an ageappropriate workup for malignancies is stressed. Due suspicion for malignancy in patients with dermatoses of unclear etiology permits an early diagnosis and appropriate treatment. The skin, thus, acts as a window on internal disorders, and hypervitaminosis B12 ought to be considered as a cancer manifestation.

\section{Consent}

The examination of the patient was conducted according to the principles of the Declaration of Helsinki.

The authors certify that they have obtained all appropriate patient consent forms, in which the patients have given consent for images and other clinical information to be included in the journal. The patients understand that their names and initials will not be published and due effort will be made to conceal their identity, but that anonymity cannot be guaranteed.

\section{REFERENCES}

1. Silva JA, Mesquita KC, Igreja ACSM, Lucas ICRN, Freitas AF, Oliveira SM, et al. Paraneoplastic cutaneous manifestations: concepts and updates. An Bras Dermatol. 2013;88:9-22.

2. Vamja CJ, Belgaumkar VA, Deshmukh NS, Tolat SN. Erythroderma: a marker for visceral malignancy: rare case report. Int J Res Dermatol. 2017;3:293-5.

3. Zulfiqar AA, Martin-Kleisch A. Hypervitaminosis B12 as an additional prognostic indicator in elderly adults with a neoplastic disease: report of a case and review of the literature. J Am Geriatr Soc. 2015;63:2220-1.

4. Arendt JF, Pedersen L, Nexo E, Sørensen HT. Elevated plasma vitamin b12 levels as a marker for cancer: a population-based cohort study. JNCI. 2013;105:1799-805.

5. Ramos-E-Silva M, Carvalho JC, Carneiro SC. Cutaneous paraneoplasia. Clin Dermatol. 2011;29:541-7.

6. Ayyamperumal A, Tharini GK, Ravindran V, Parveen B. Cutaneous manifestations of internal malignancy. Indian J Dermatol. 2012;57:260-4.

7. Hassan I, Zeerak S, Kuchay S, Bashir S, Bhat YJ, Mubashir S, et al. Cutaneous changes in internal malignancy: Study from a tertiary care center. Indian J Dermatol Venereol Leprol. 2017;83:276.

8. Aqil N, Nassiri A, Baybay H, Douhi Z, Elloudi S, Mernissi FZ. Erythroderma: A clinical and etiological study of 92 patients. Our Dermatol Online. 2019;10:1-6.

9. Khoschbin T, Löser C, Dippel E. [Paraneoplastic skin diseases]. Internist (Berl). 2019;60:775-82.

10. McGaw B, McGovern VJ. Exfoliative dermatitis associated with carcinoma of the lung. Aust J Dermatol. 1956;3:115-9.

11. Gupta A, Gupta S, Awad OAA, Estrada-y-martin RM. Case In Point: Exfoliative dermatitis: A presenting sign of lung cancer. Lung Cancer. 2005:1.

12. Kanwar AJ, Narang T. Anagen effl uvium. Indian J Dermatol Venereol Leprol. 2013;79:604-12.

13. Carmel R. Extreme elevation of serum transcobalamin I in patients with metastatic cancer. N Engl J Med. 1975;292:282-4.

14. Andrès E, Serraj K, Zhu J, Vermorken AJ. The pathophysiology of elevated vitamin B12 in clinical practice. QJM. 2013;106:505-15.

15. Zulfiqar AA, Sebaux A, Andres E, Novella JL. Hypervitaminia B12: An unknown endocrine marker. J Food Nutr Sci. 2015;3:32-4.

16. Arendt JFH, Sørensen HT, Horsfall LJ, Petersen I. Elevated vitamin b12 levels and cancer risk in uk primary care: a thin database cohort study. Cancer Epidemiol Biomarkers Prev. 2019;28:814-21.

Copyright by Seetharampura Ramamurthy Radhika, et al. This is an open access article distributed under the terms of the Creative Commons Attribution License, which permits unrestricted use, distribution, and reproduction in any medium, provided the original author and source are credited.

Source of Support: Nil, Conflict of Interest: None declared. 